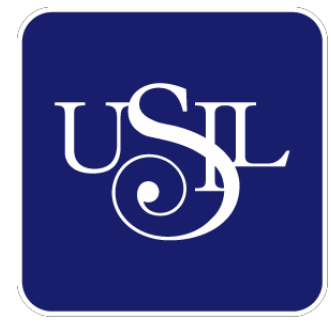

UNIVERSIDAD

SAN IGNACIO

DE LOYOLA

ESCUELA DE POSTGRADO

Maestría en Administración de Negocios y Emprendimiento

\title{
PLAN DE NEGOCIOS PARA LA CREACIÓN DE UNA INSTITUCIÓN EDUCATIVA INICIAL PRIVADA EN LOS DISTRITOS DE LOS OLIVOS Y SAN MARTIN DE PORRES
}

Trabajo de Investigación para optar el grado de Maestro en Administración de Negocios y Emprendimiento

\author{
MARGOT CERNA ROJAS \\ ROCIO KARIM COLLAO DIAZ \\ LIZBETH HAYDEE PAZ IBARRA \\ PEDRO FERNANDO POLO TEJEDA
}

Asesora:

Nidia Vílchez Yucra

Lima - Perú

2018 



\section{"PLAN DE NEGOCIO PARA LA CREACIÓN DE UNA INSTITUCIÓN EDUCATIVA INICIAL PRIVADA EN LOS DISTRITOS DE LOS OLIVOS Y SAN MARTIN DE PORRES”}




\section{Agradecimiento:}

A Dios, a mi querido esposo Renato y adorada hijita Danna, por su comprensión, amor, tolerancia y motivación, durante todo este tiempo.

A mi Mayecita quien sufrió mis desvelos y a mi Daddy querido, quien me enseñó a cumplir con mi deber a costa de TODO, mi agradecimiento eterno, para ustedes. Vamos por mas...

Lizbeth Paz Ibarra

El presente trabajo tuvo grandes retos que debimos enfrentar para su culminación y como todo principio tiene su final este es el resultado. En lo particular agradezco a mi esposo Edwin que desde un inicio me brindó su apoyo incondicional, por su comprensión en cada ausencia y amanecida a lo largo del desarrollo de la maestría; a mis hijos Karim, Rafael y Edwin Junior que son el empuje y motor de superación personal, a mis padres Manuel y Paquita que a pesar de ser adulta siempre están presentes con su apoyo infinito y aunque ahora no te das cuenta de mis logros papito lindo sé que en el fondo sientes cada satisfacción y superación que tengo en la vida.

Gracias a DIOS y a la vida por guiarme en cada instante a poder tomar conciencia que en esta sociedad no solo basta cumplir los retos, es muy importante considerar el factor humano.

Rocío Collao Díaz

A mis padres, por haberme apoyado en todo momento, sobre todo en los días más difíciles, siempre motivándome para salir adelante.

Pedro Polo Tejeda 
No fue sencillo terminar este proyecto, gracias Marco por tu amor, cariño y comprensión, por estar ahí en los momentos más difíciles.

A mi estrellita Mariana...este logro es para ti mi amor.

A mis padres Juana y Marcelo quienes me inculcaron humildad y superación, gracias por su motivación y a mi hermano Jorge, gracias a su regalo inicie este camino que hoy concluyo.

Margot Cerna Rojas 


\section{Resumen Ejecutivo}

El presente Plan de Negocios tiene como finalidad la creación de una Institución Educativa Inicial Privada, que tendrá como nombre Sonajas \& Crayolas, la cual brindará un servicio diferenciado, teniendo como ventaja competitiva: Gestionar el conocimiento, entendiéndose como el conjunto de procesos y sistemas que contribuyen a aumentar en el capital humano, las capacidades de resolver los problemas de forma eficiente, modelando procesos que respondan a los cambios internos y del entorno, impulsando la aplicación de la mejora continua, logrando que el conocimiento se convierta en patrimonio de la organización. Complementado con otros servicios: Personal altamente calificado y bien remunerado; moderna infraestructura; horarios extendidos; talleres de integración familiar y ubicación estratégica, en síntesis, ofrecer un servicio innovador e integrador.

El proyecto estará ubicado en el distrito de Los Olivos para los años 2018 - 2027 (horizonte del proyecto), esto se justifica por el resultado de las encuestas y análisis de los factores locacionales, sobre todo por la concentración de hogares de los NSE A y B, además de no existir presencia de competidores directos que ofrezcan el servicio educativo exclusivo a niños del nivel inicial en la zona. Por otro lado, se espera un entorno económico, social, político, ambiental, legal favorable en los próximos años, que permita a los padres de familia apostar por la propuesta, convencidos que la educación en la temprana edad, basada en el desarrollo integral de los niños, permitirá el desarrollo mental, físico, emocional y social, con la participación activa de los padres de familia y de la Comunidad Educativa.

Con respecto a los factores de posicionamiento, se busca que los padres de familia perciban que los beneficios que podrían recibir superen enormemente los costos de la matrícula, pago de la pensión mensual e inclusive la cuota de ingreso. 
En el estudio de ingeniería, se plantea que la I.E.I.P. Sonajas \& Crayolas cuente con tres etapas, en los dos primeros años se aperturará tres salones con capacidad para 25 alumnos por aula y a partir del año tres se construirá tres aulas adicionales, incrementando la capacidad instalada total a 150 alumnos, en la tercera etapa que es a partir del 5 to año se evaluará y realizará el estudio de mercado para definir la compra y construcción de otro local con 3 aulas del nivel inicial o posible apertura del nivel primario.

Se determinó que el valor de la pensión escolar por cada niño será de S/. 600.00 (10 cuotas al año), el costo de matrícula de S/. 600.00 (pago anual), en tanto que la cuota de ingreso será S/. 520.00 (pago único). De acuerdo al presupuesto de ventas estos costos se incrementarían a partir del 5to año una vez que se logre la cobertura al 100\% y se haya logrado posicionar la marca de acuerdo al plan de marketing.

Para la puesta en marcha del presente proyecto se debe de contar con una inversión de S/ 1'529,552; el 72.17\% será producto de los aportes de los accionistas y el 27.83\% restante corresponderá al financiamiento con la entidad bancaria MI BANCO, cuya tasa efectiva anual es de $15.36 \%$ pagadero a 10 años; esta inversión corresponde principalmente a la compra de un terreno de $450 \mathrm{mt} 2$, mobiliario, equipos diversos, entre otros. El tiempo de recuperación de la inversión del accionista es de cinco años once meses y 19 días.

Al determinar el flujo económico bajo las condiciones detalladas en el párrafo anterior se obtendrá que el proyecto presenta un VANE positivo de S/ 776,349, VANF S/ 577,472 con un TIRE del $24.97 \%$, y TIRF de $27.73 \%$ por lo tanto, se concluye que el plan de negocio propuesto es viable y rentable.

Por último, se espera un impacto positivo en la sociedad al brindar educación de calidad e integrar a la familia con una visión de largo plazo de la educación aportando al desarrollo humano y social, es desarrollo integral del niño y su entorno. 


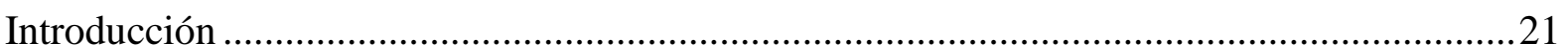

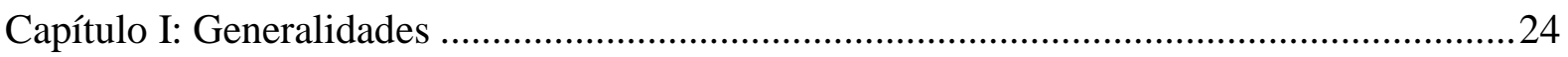

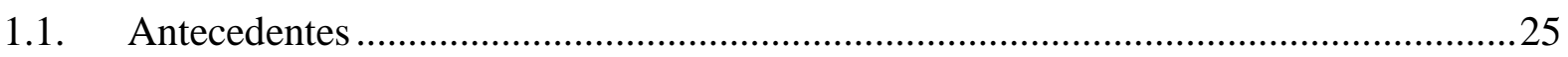

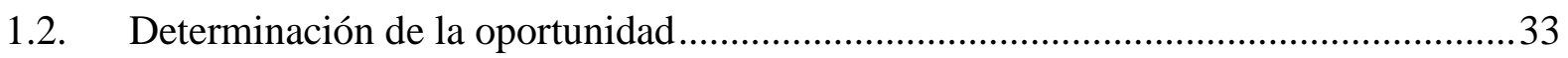

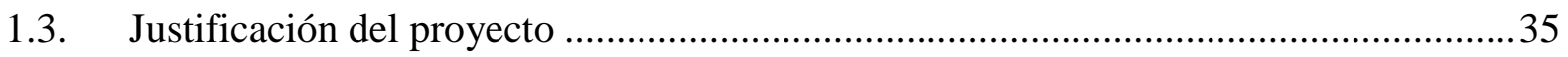

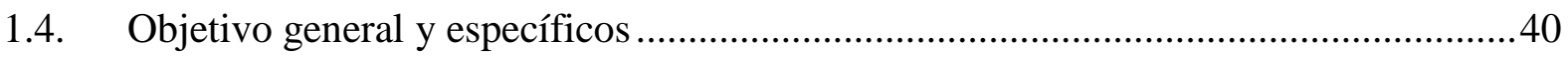

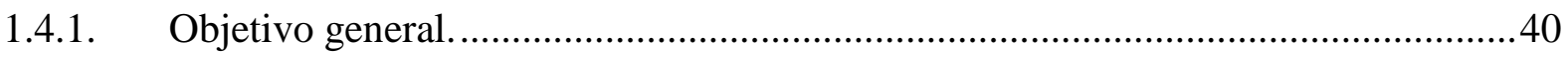

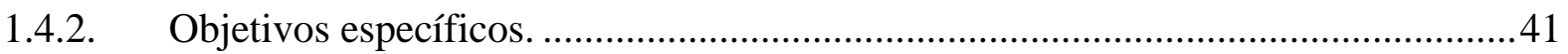

1.5. Alcances y limitaciones de la investigación ............................................................... 41

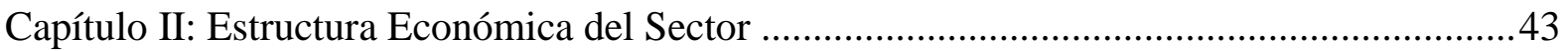

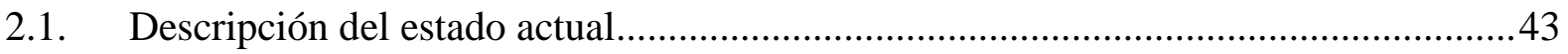

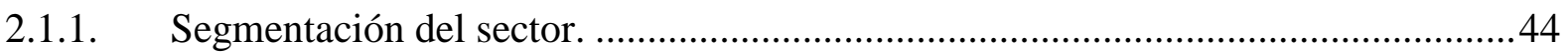

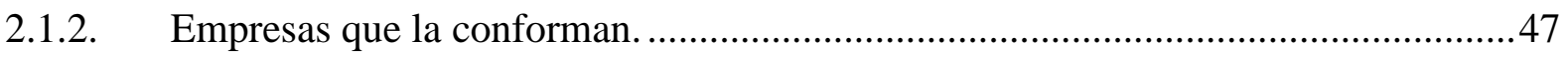

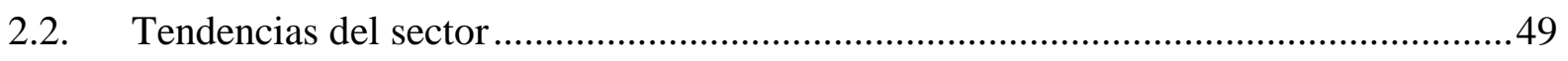

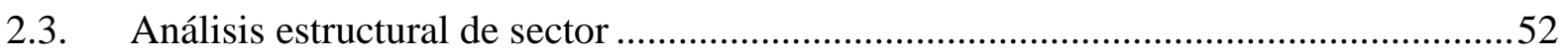

2.3.1. Poder de negociación de los clientes (fuerza 1) .................................................53

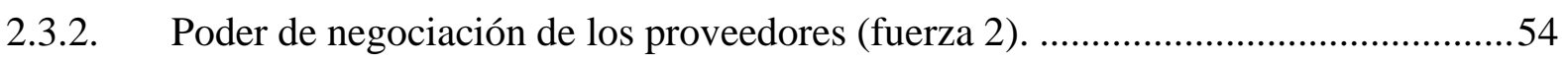

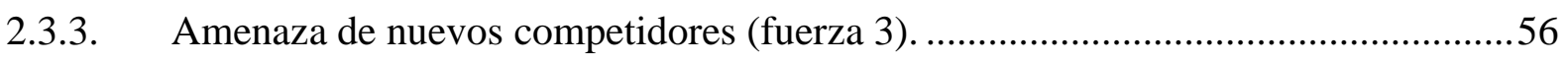

2.3.4. Amenaza de productos o servicios sustitutos (Fuerza 4) .....................................58

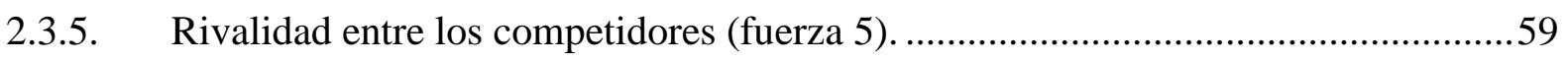

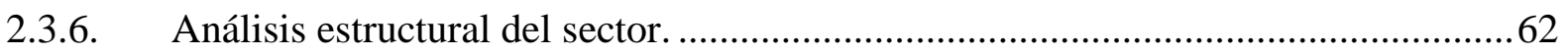

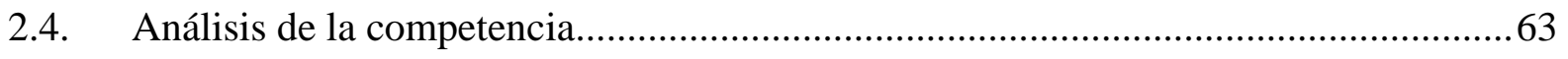

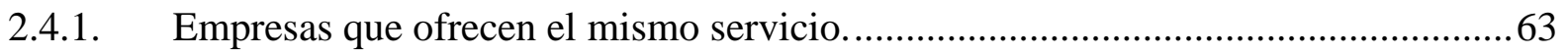


2.4.2. Participación de mercado de cada uno de ellos.

2.4.3. Matriz de perfil competitivo.

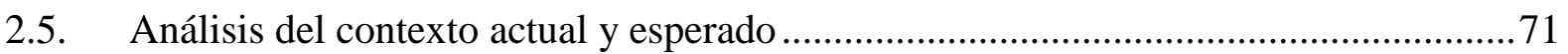

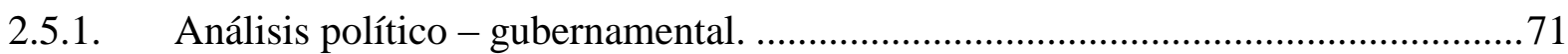

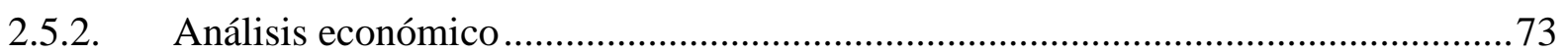

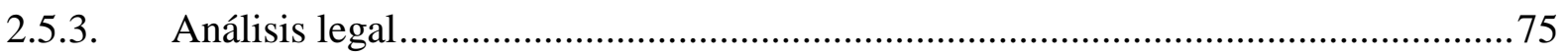

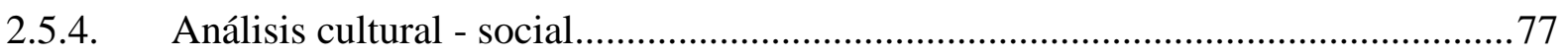

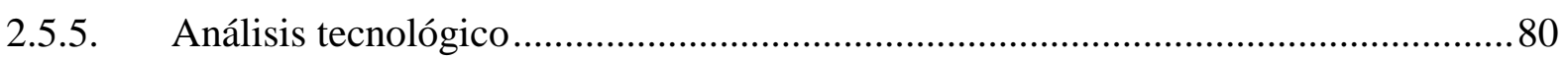

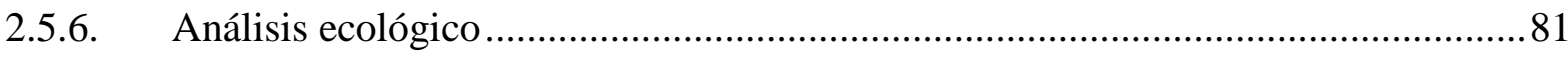

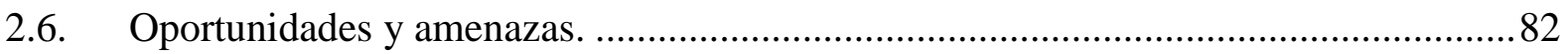

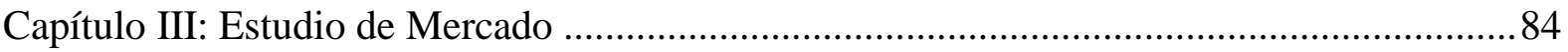

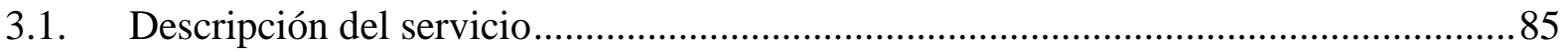

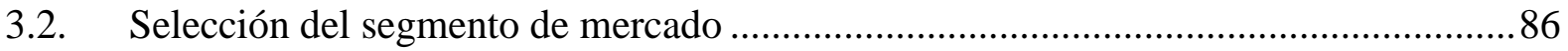

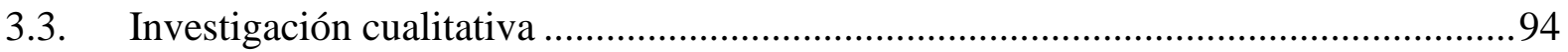

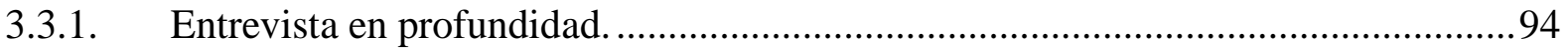

3.3.2. Proceso de muestreo de la entrevista en profundidad.........................................95

3.3.3. Diseño de instrumento de la entrevista en profundidad........................................96

3.3.4. Análisis y procesamiento de datos de la entrevista a profundidad. ........................96

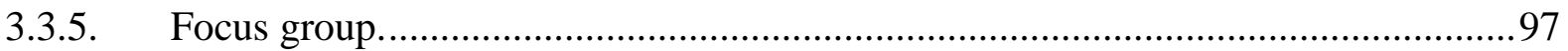

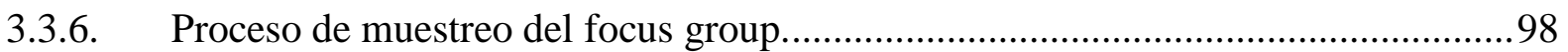

3.3.7. Diseño de instrumento del focus group. ........................................................... 99

3.3.8. Análisis y procesamiento de datos del focus group..............................................99

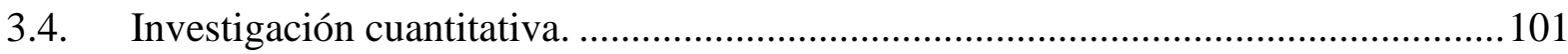

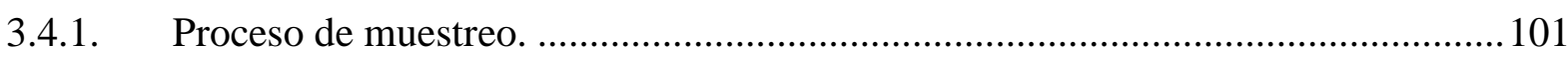

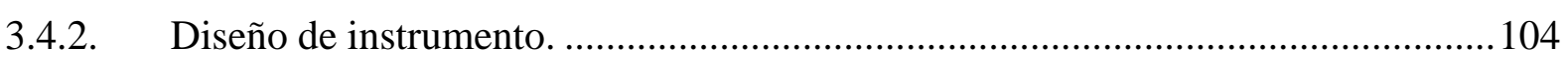

3.4.3. Análisis y procesamiento de datos de la investigación cuantitativa. ...................... 104 
3.5. Conclusiones y recomendaciones del estudio cualitativo y cuantitativo.

3.6. Perfil del consumidor.

Capítulo IV: Proyección del Mercado Objetivo ...................................................................... 115

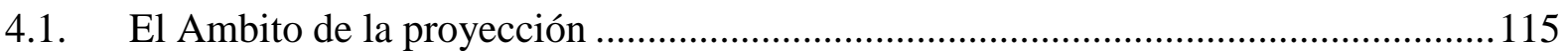

4.2. Selección del método de proyección............................................................................... 119

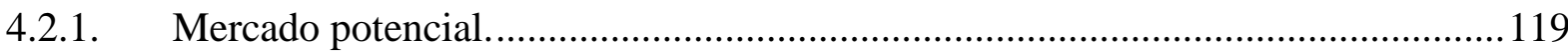

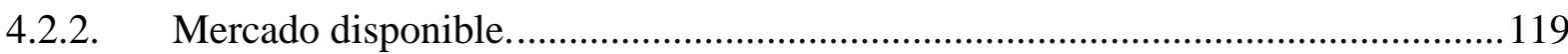

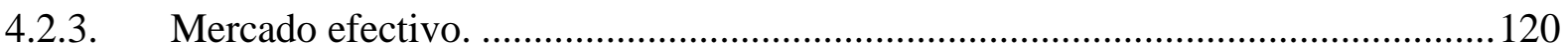

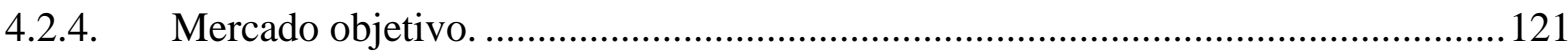

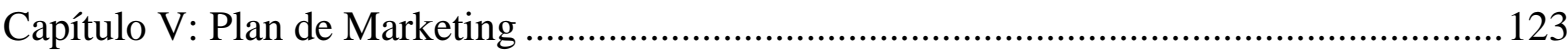

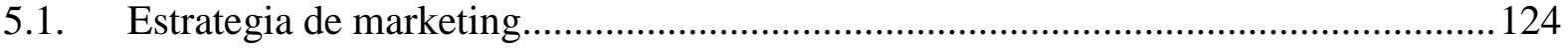

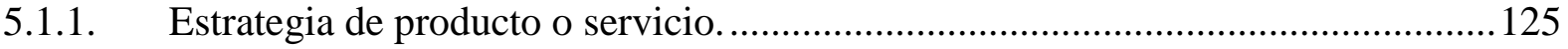

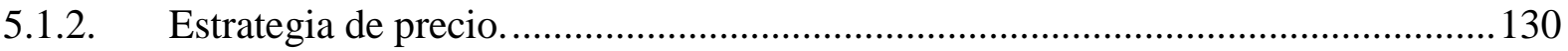

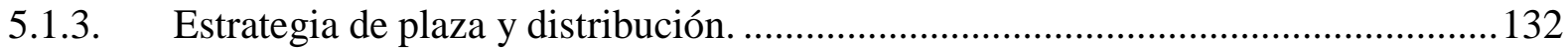

5.1.4. Estrategia de promoción y publicidad...................................................................... 132

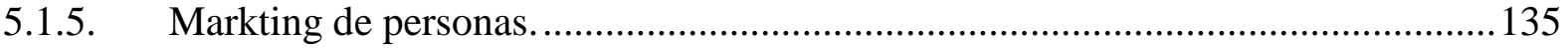

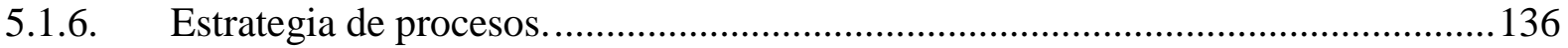

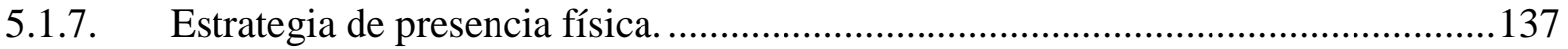

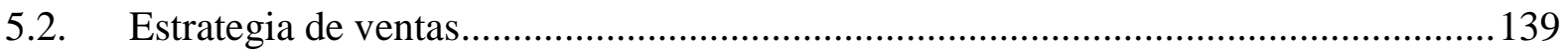

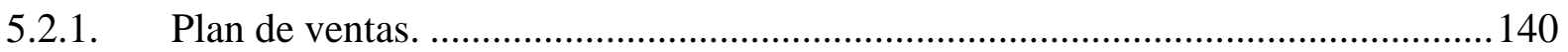

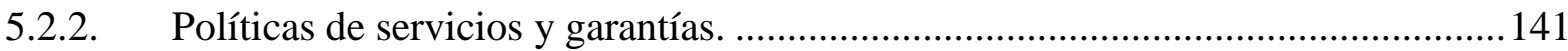

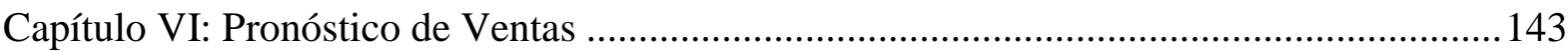

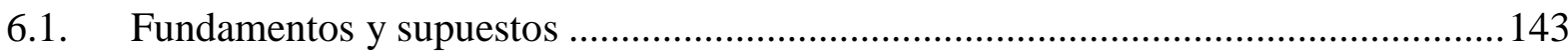

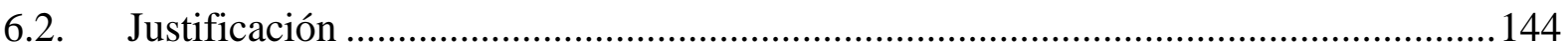

6.3. Análisis de riesgos y aspectos críticos que impactan en el pronóstico ....................... 146

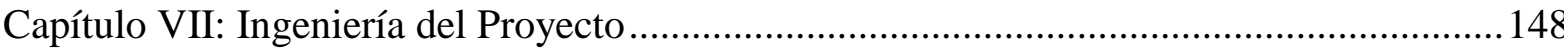




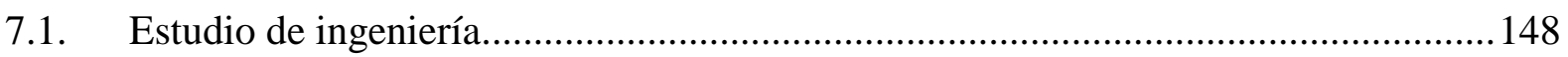

7.1.1. Modelamiento y selección de procesos productivos.................................................... 148

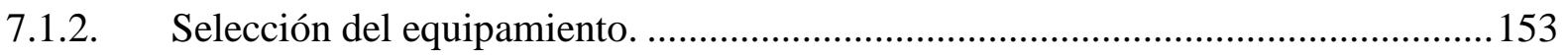

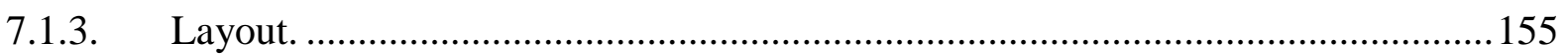

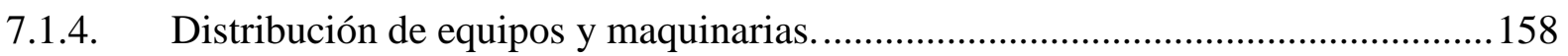

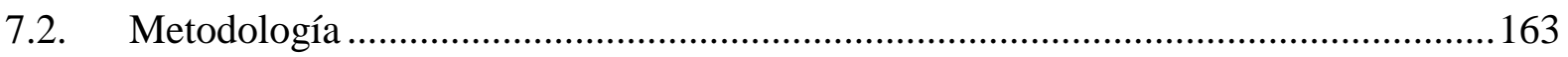

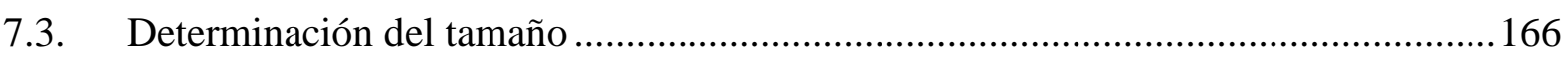

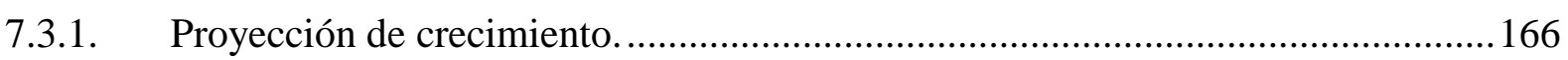

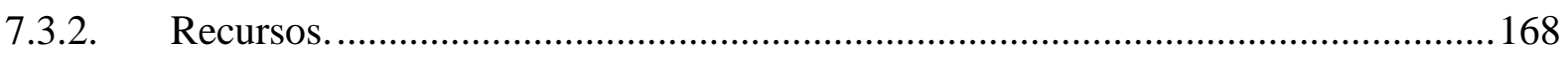

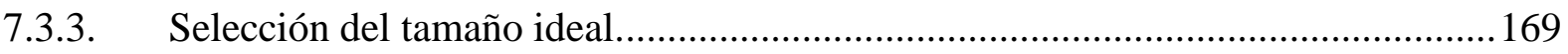

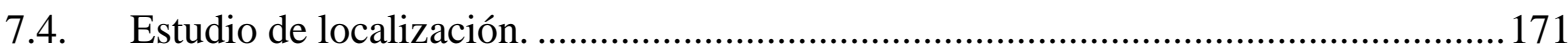

7.4.1. Definición de factores locacionales. ..................................................................... 171

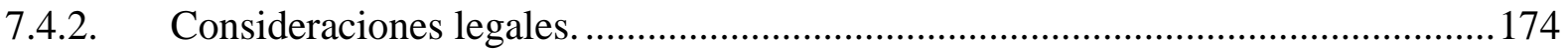

7.4.2.1. Identificación del marco legal......................................................................... 174

7.4.2.2. Ordenamiento jurídico de la empresa. .............................................................. 178

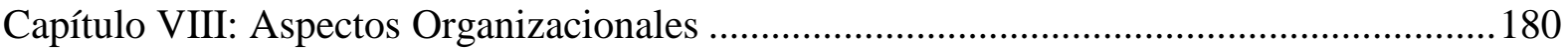

8.1. Caracterización de la cultura organizacional deseada ...............................................180

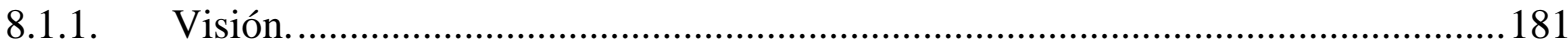

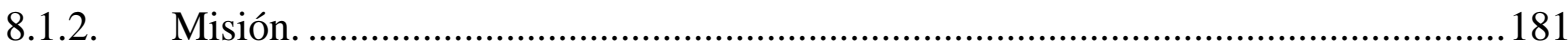

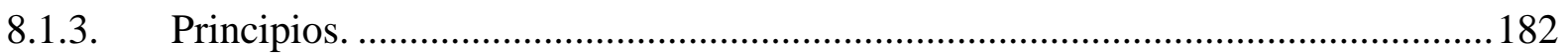

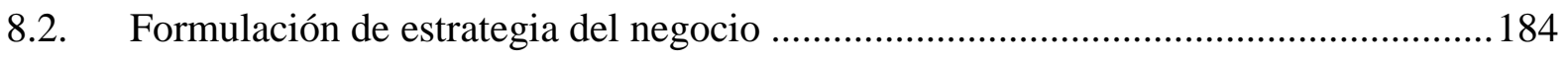

8.3. Determinación de las ventajas competitivas críticas ....................................................184

8.4. Diseño de la estructura organizacional deseada.......................................................... 185

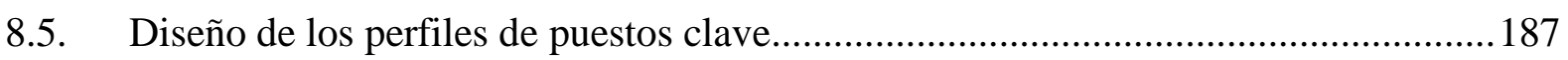

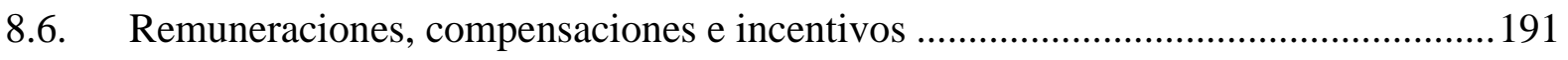

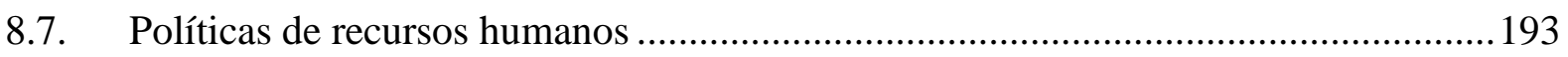


Capítulo IX: Planificación Financiera.

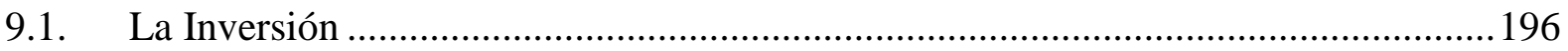

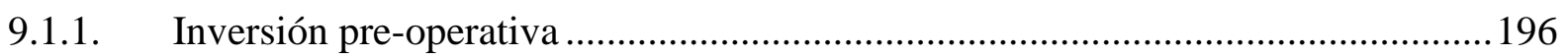

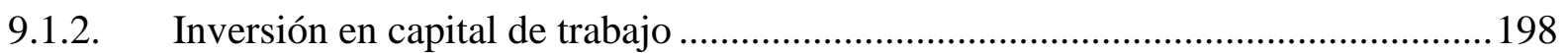

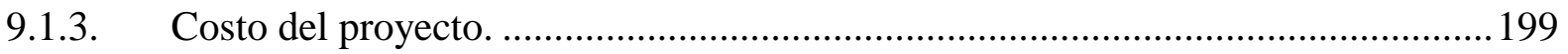

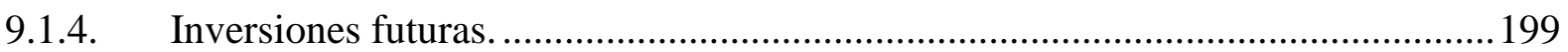

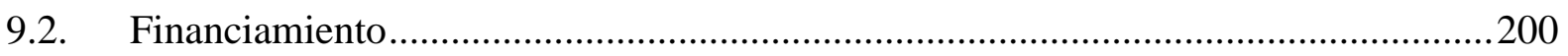

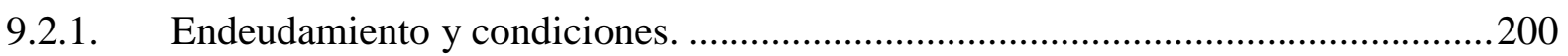

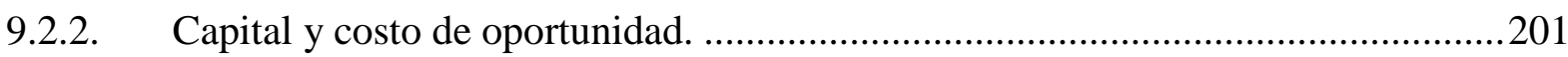

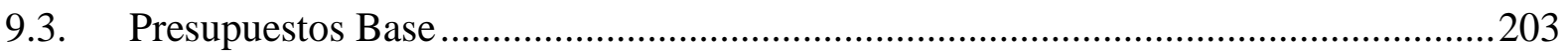

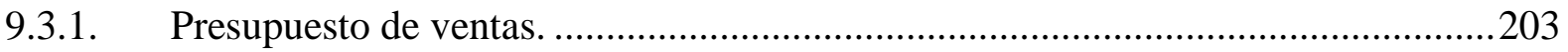

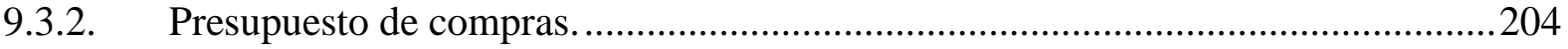

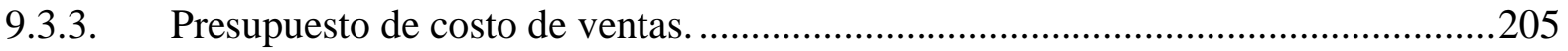

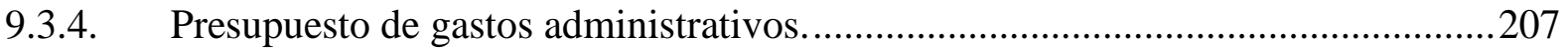

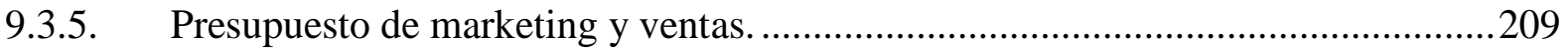

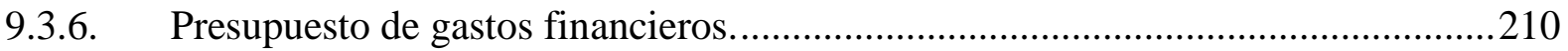

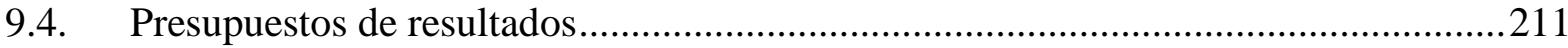

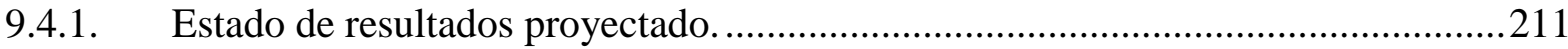

9.4.2. Estado de situación financiera proyectado.........................................................213

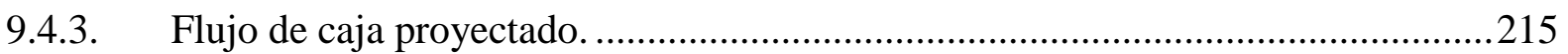

Capítulo X: Evaluación Económica Financiera ...................................................................217

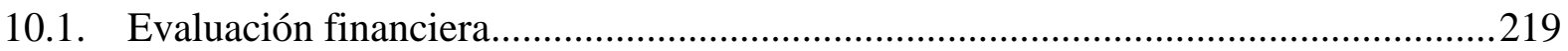

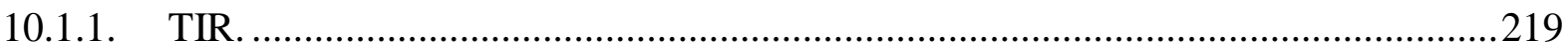

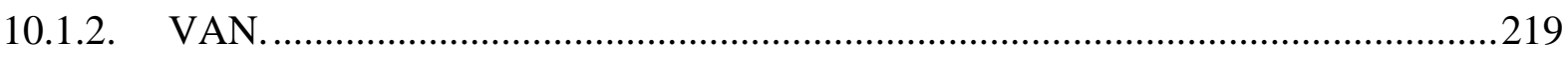

10.1.3. ROE

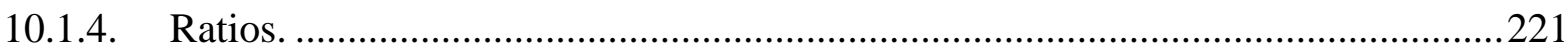




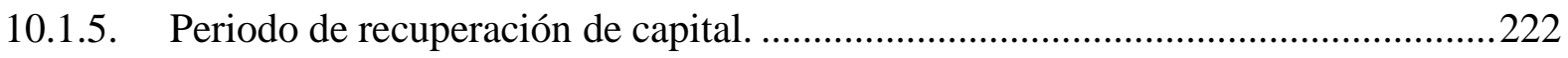

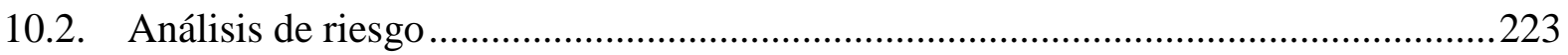

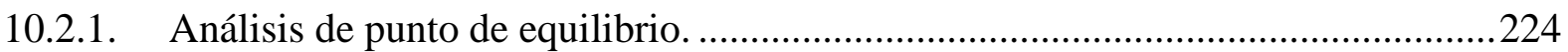

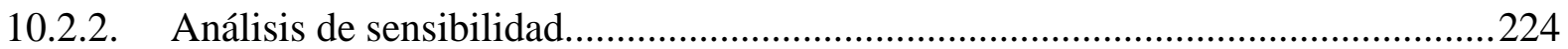

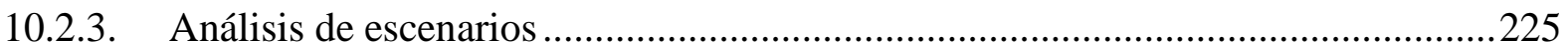

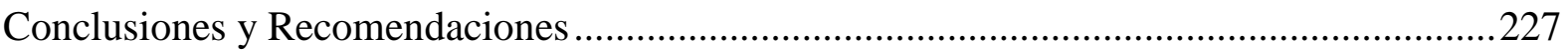

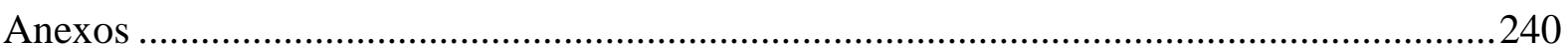


Tabla 2 Matrículas de niños de tres a cinco años del nivel inicial por zonas en Lima

Metropolitana

Tabla 3 Número de docentes nivel inicial en Lima Metropolitana 2008 - 2017. .28

Tabla 4 Histórico de los niveles socioeconómicos en Lima Metropolitana por zonas 2011 2017

Tabla 5 Brecha existente entre población total de niños y matrículas de niños entre tres y cinco años .35

Tabla 6 Distribución de IIEE nivel inicial privado en Lima Norte - 2017. .39

Tabla 7 Lima Norte: Superficie y densidad según distritos 2017 40

Tabla 8 Distribución de Instituciones Educativas nivel inicial, zonas según el tipo de gestión en

Lima .46

Tabla 9 Segmentación del sector educación en Los Olivos y San Martín de Porres 47

Tabla 10 Principales Instituciones Educativas de nivel inicial en Los Olivos y San Martin de Porres

Tabla 11 Análisis del poder de negociación con los clientes .54

Tabla 12 Análisis del poder de negociación con los proveedores. .55

Tabla 13 Análisis de la amenaza de competidores potenciales .57

Tabla 14 Análisis de la amenaza de productos o servicios sustitutos .59

Tabla 15 Análisis De La Rivalidad Entre Competidores.

Tabla 16 Evaluación de las fuerzas competitivas de porter según su fuerza e importancia del sector.

Tabla 17 Principales competidores de nivel inicial en Los Olivos y San Martin de Porres 64 
Tabla 18 Participación de Mercado de las IIEE nivel inicial

Tabla 19 Matriz de perfil competitivo y ponderación de los factores críticos de éxito de las

IIEE .70

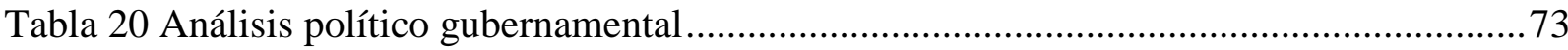

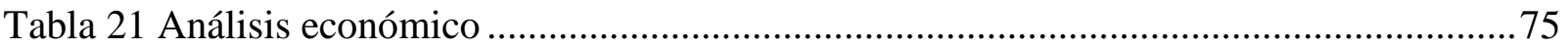

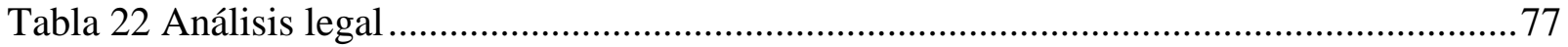

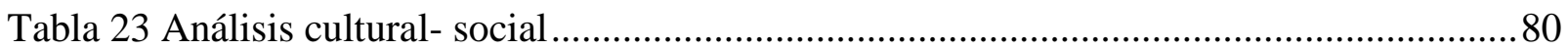

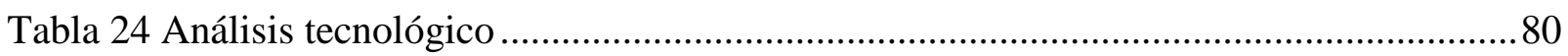

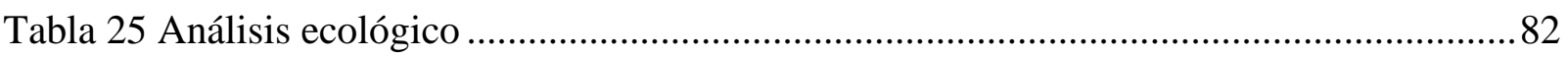

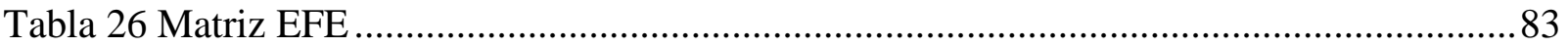

Tabla 27 Ficha técnica de investigación de mercado ............................................................... 84

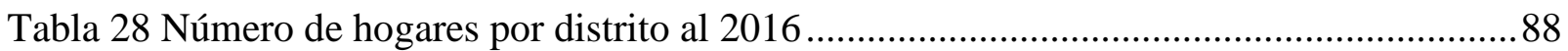

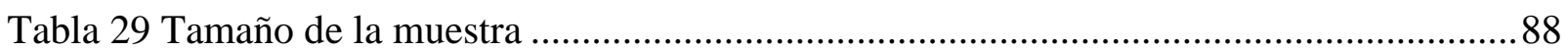

Tabla 30 Resultado de la encuesta para determinar la cantidad niños entre tres y cinco años ..92

Tabla 31 Objetivos de la entrevista en profundidad................................................................ 95

Tabla 32 Matriz de resultados de la entrevista en profundidad..............................................97

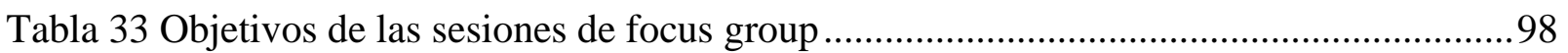

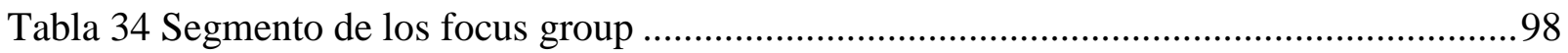

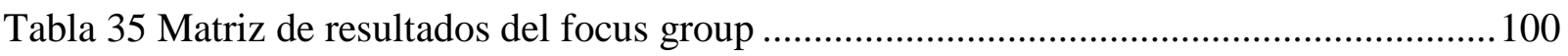

Tabla 36 Fuentes de información secundaria- análisis cualitativo........................................ 101

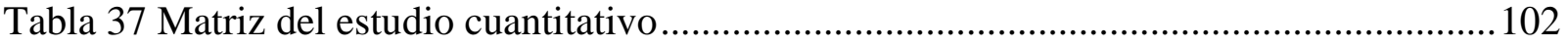

Tabla 38 Decisión de matrícula en alguna institución educativa inicial particular................... 105

Tabla 39 Nivel de satisfacción de los padres de familia ...................................................... 105

Abla 40 Percepción de los padres de familia sobre el servicio ............................................. 106

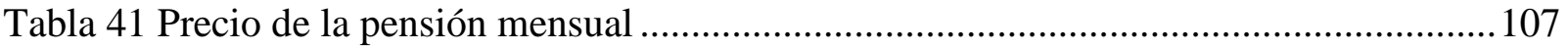


Tabla 42 Motivo de los padres para cambiar de institución educativa

Tabla 43 Puntuación de los atributos valorados por los padres de familia 108

Tabla 44 Decisión de compra. 109

Tabla 45 Monto de la pensión que los padres están dispuestos a pagar. 110

Tabla 46 Percepción del nombre de la I.E.I 110

Tabla 47 Determinación del mercado potencial

Tabla 48 Determinación del mercado disponible 120

Tabla 49 Porcentaje para el cálculo del mercado efectivo

Tabla 50 Determinación del mercado efectivo

Tabla 51 Matrículas privadas de ebr nivel inicial de tres a cinco años por distrito y gestión.. 122

Tabla 52 Determinación del mercado objetivo

Tabla 53 Presupuesto de estrategias

Tabla 54 Proyección de crecimiento del año uno al año diez 140

Tabla 55 Plan de ventas del año uno al año diez 141

Tabla 56 Presupuesto de ventas del año uno al año diez 145

Tabla 57 Sectores para el aula de inicial 155

Tabla 58 Equipos y mobiliario de oficina de dirección y recepción 159

Tabla 59 Equipos y mobiliario sala de profesores 160

Tabla 60 Equipos y mobiliario de aulas 161

Tabla 61 Mobiliario para el desarrollo psicomotriz y físico 162

Tabla 62 Equipos y mobiliario de tópico 162

Tabla 63 Tipos de metodologías aplicadas a la educación nivel inicial. 163

Tabla 64 Horarios establecidos para la I.E.I.P Sonajas y Crayolas 164

Tabla 65 Organización de la ebr nivel inicial y planes de estudio 164

Tabla 66 Actividades y momentos pedagógicos 165 
Tabla 67 Proyección de crecimiento del año uno al año diez.

Tabla 68 Determinación del tamaño ideal - I.E.I.P Sonajas \& Crayolas

Tabla 69 Determinaciódel tamaño ideal - I.E.I.P - Primer Nivel

Tabla 70 Determinación del tamaño ideal - I.E.I.P - Segundo Nivel.

Tabla 71 Determinación de factores locacionales

Tabla 72 Remuneraciones y beneficios

Tabla 73 Gastos outsourcing

Tabla 74 Inversión intangible.

Tabla 75 Inversión tangible

Tabla 76 Costo total

Tabla 77 Inversión tangible futura

Tabla 78 Forma de financiamiento

Tabla 79 Estructura del financiamiento

Tabla 80 Estimación del CAPM.

Tabla 81 Costo capital promedio ponderado.

Tabla 82 Presupuesto de ventas

Tabla 83 Presupuesto de ventas del año uno al año diez 204

Tabla 84 Presupuesto de compras .... 204

Tabla 85 Presupuesto de compras del año uno al año diez 205

Tabla 86 Personal - capacidad por cubrir y remuneraciones 206

Tabla 87 Presupuesto de costo de ventas del año uno al año diez 206

Tabla 88 Gastos administrativos 207

Tabla 89 Planilla personal administrativo 208

Tabla 90 Presupuesto de gastos administrativos del año uno al año diez 208

Tabla 91 Gastos de marketing y ventas .209 
Tabla 92 Presupuesto de marketing y ventas del año uno al año diez

Tabla 93 Presupuesto gastos financieros del año 1 al año 10

Tabla 94 Estado de resultados proyectado del año uno al año diez

Tabla 95 Estado de situación proyectado del año uno al año diez

Tabla 96 Flujo de caja económico y financiero proyectado del año uno al año diez 216

Tabla 97 Estimación del flujo a perpetuidad 218

Tabla 98 Estimación de la TIR y el VAN 220

Tabla 99 Análisis ROE del año uno al año diez .221

Tabla 100 Cálculos de principales ratios del año uno al año diez. 221

Tabla 101 Determinación de la recuperación de la inversión del accionista 223

Tabla 102 Determinación de la recuperación de capital descontado 223

Tabla 103 Punto de equilibrio del año uno al año diez 224

Tabla 104 Análisis de sensibilidad por costo 225

Tabla 105 Análisis de sensibilidad por ventas 225

Tabla 106 Análisis de escenarios 226

Tabla 107 Análisis de riesgos por categoria. 227 
Figura 1. Número de instituciones educativas nivel inicial en Lima Metropolitana 2008 - 2017

Figura 2. Crecimiento de los hogares en Lima Metropolitana ...............................................29

Figura 3. Distribución de Lima Metropolitana por zonas. .................................................... 37

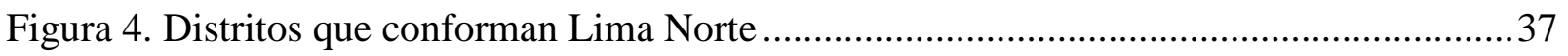

Figura 5. Ubicación de las principales IIEE .................................................................... 48

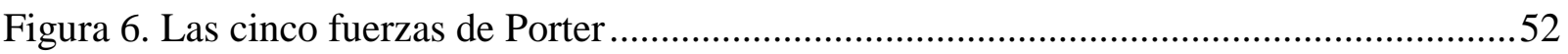

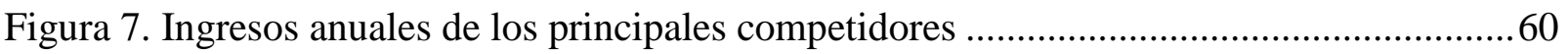

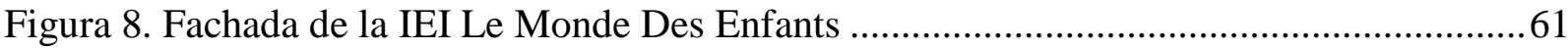

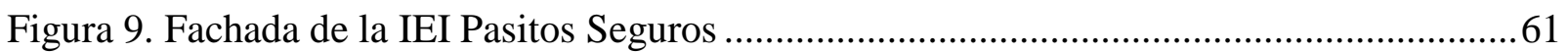

Figura 10. Ubicación de las IIEE mas reconocidas en Los Olivos y San Martín de Porres ......66

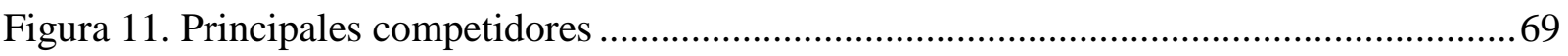

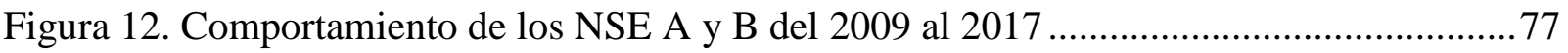

Figura 13. Población y manzanas de los NSE A y B en los distritos de Los Olivos y San Martin

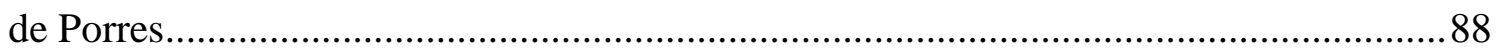

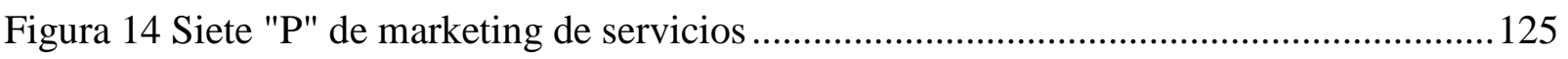

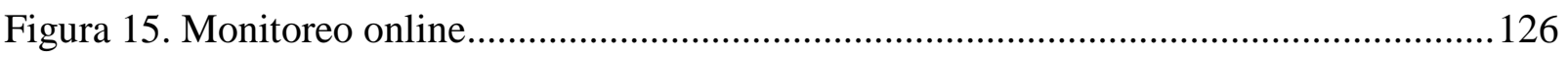

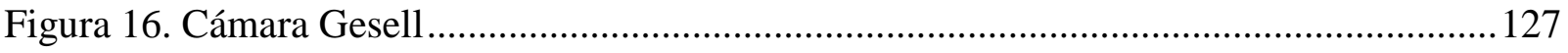

Figura 17. Infraestructura moderna y ecológica.............................................................. 128

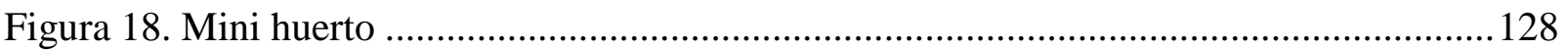

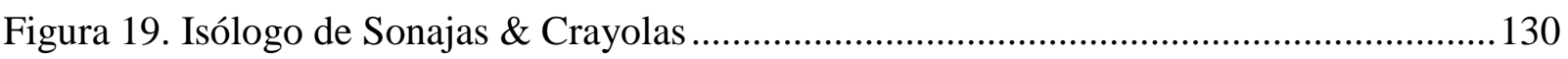

Figura 20. Gantt de actividades de IEIP Sonajas \& Crayolas ............................................. 135

Figura 21. Objetivos específicos Sonajas \& Crayolas .......................................................... 138 


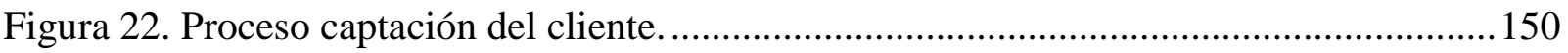

Figura 23. Sub proceso exámen de selección.........................................................................151

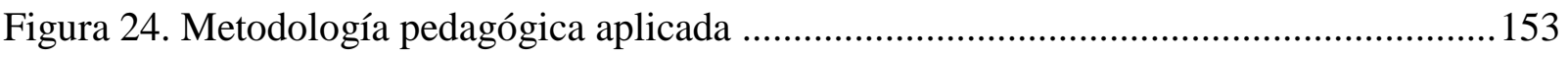

Figura 25. Ambiente pedagógico para niños de tres a cinco años. .............................................154

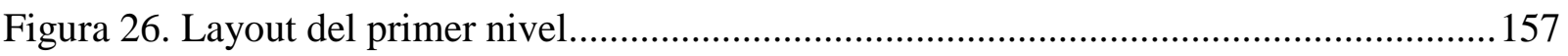

Figura 27. Layout del segundo nivel ................................................................................157

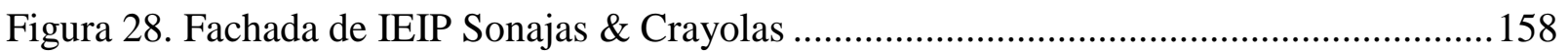

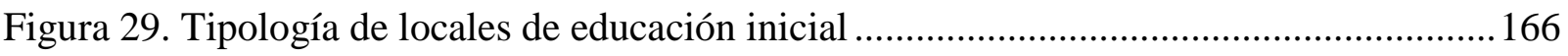

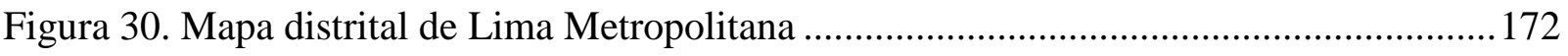

Figura 31. Procedimiento para obtención de licencia de funcionamiento .................................174

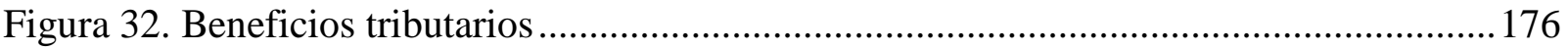

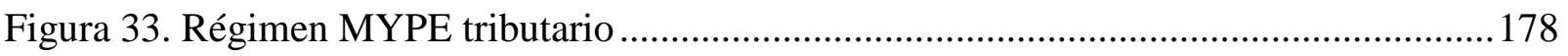

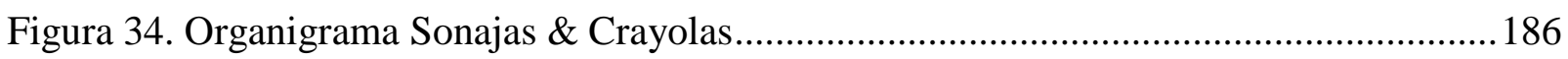

Figura 35. Perfil puesto clave - director IEIP .................................................................... 187

Figura 36. Perfil puesto clave - coordinador académico de la IEIP ......................................... 188

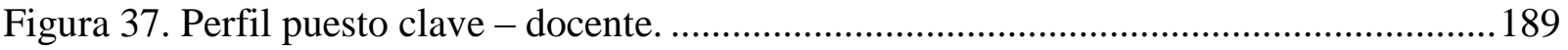

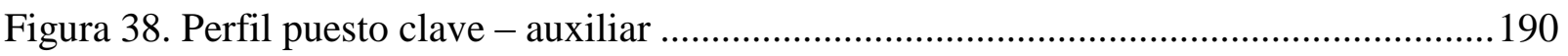




\section{Introducción}

La educación es el eje fundamental para la transformación de la sociedad y los padres de familia, en cooperación con la comunidad educativa juegan un rol muy importante, para lograr el desarrollo integral de los niños desde la temprana edad.

En el Artículo 17 de la Constitución Política del Perú se establece que la educación inicial, primaria y secundaria son obligatorias, pero no se da pleno cumplimiento en el nivel inicial, puesto que no es requisito haber cursado inicial para matricular a un niño en primer grado de educación primaria. El Ministerio de Educación (2016) en su Oficio №2738-2016 sostiene: "En el Perú el nivel de educación inicial no es obligatorio, lo cual genera desventajas en el aprendizaje en la mayoría de los estudiantes peruanos, que no tienen acceso a la EBR" (p. 7).

Asimismo, muchos padres de familia reconocen que la educación no debe esperar, al respecto el Ministerio de Educación (2013) realizó un Estudio relacionado a Educación Inicial y donde responde a la pregunta ¿Por qué es importante que los niños asistan a la educación inicial?:

Es importante porque la asistencia a Educación Inicial favorece el desarrollo integral de los niños. En los últimos años, la Educación Inicial ha adquirido gran importancia debido a su contribución al desarrollo cognitivo, social y emocional del niño. En general, las evidencias de investigaciones de disciplinas como la psicología, la nutrición y las neurociencias demuestran que los primeros años de vida son fundamentales para el desarrollo de la inteligencia, personalidad y socialización. (p. 4)

Por otro lado, a los padres de familia les preocupa el clima de violencia imperante. Así lo señala el Ministerio de Educación (2012) “La violencia está presente en muchas 
instituciones educativas de nuestro país desde hace mucho tiempo. Este fenómeno se ha convertido en una preocupación de las autoridades educativas y de la comunidad en general debido a los niveles alcanzados" (p. 4).

Por otro lado el Ministerio de Educación (2017), lanzó la campaña preventiva “El bullying no da risa, reportemos", a fin de disminuir la violencia en las escuelas.

Ante lo señalado los padres de familia buscan una opción que les garantice la seguridad, la limpieza, buena infraestructura que respete la Norma Técnica para el Diseño de Locales de EBR Nivel Inicial del (2014), la calidad educativa a todo nivel, sin embargo, los padres de familia no encuentran una Institución Educativa Inicial (I.E.I.) que reúna o cumpla con todos los atributos que ellos necesitan y esperan, optando por matricularlos en una I.E.I. que se encuentra cerca de casa por la comodidad que eso representa.

El desarrollo del trabajo comprende los siguientes capítulos:

Capítulo I: Define el ámbito de evaluación, presenta los antecedentes del tema, se describe la oportunidad y la justificación del plan de negocio, así como los objetivos, alcances y limitaciones que deben ser considerados.

Capítulo II: Se realiza un análisis del entorno macroeconómico y microeconómico, se estudia el sector educación, se define a los competidores directos e indirectos y se determinan las oportunidades y amenazas del sector.

Capítulo III: Se muestra el desarrollo del estudio de mercado a través de una investigación cualitativa con entrevistas y focus group y una investigación cuantitativa a través de un cuestionario aplicado a una muestra representativa, identificando la necesidad y determinando el público objetivo dispuesto a invertir en una educación de calidad. 
Capítulo IV: Se define el ámbito de proyección y la determinación de los mercados potencial, disponible, efectivo y objetivo, con los cuales se plantea la demanda y se realiza las proyecciones de venta del proyecto.

Capítulo V: Se define el plan de marketing, mostrando y definiendo a detalle el producto, los niveles de precios a plantear, el canal de ventas y las acciones de publicidad y promoción, además de las estrategias de ventas.

Capítulo VI: Se define el fundamento, justificación y análisis de riesgo que afectan el pronóstico de ventas.

Capítulo VII: Se elabora el estudio de ingeniería, diseño, determinación del tamaño, la macro y micro localización óptima del proyecto y se define los procesos de atención del servicio, recursos y metodología necesarios para abastecer la demanda proyectada.

Capítulo VIII: Tiene por objeto determinar los aspectos organizacionales del proyecto, teniendo en cuenta la cultura organizacional, estrategia de negocio y política de recursos humanos.

Capítulo IX: Muestra la planificación financiera, el nivel de inversiones compuesto por activos fijos, inversión pre operativa y el capital de trabajo, fuentes de financiamiento. Define también los presupuestos de ingresos, costos de producción, gastos administrativos y de ventas, además del estado de resultados, balance general y flujos de caja.

Capítulo X: Muestra los indicadores de rentabilidad del proyecto, así como el análisis de punto de equilibrio y sensibilidad.

Capítulo XI: Se detalla las conclusiones y recomendaciones producto del presente trabajo. 